\title{
Diagnostic Yield of Upper Gastrointestinal Endoscopy in Children: A Three Years Experience
}

\section{Binita Gurubacharya Joshi and Madhu Ghimire}

Department of Digestive Disease Centre, Norvic International Hospital, Thapathali, Kathmandu, Nepal

\section{Correspondence: \\ Binita Gurubacharya Joshi \\ Consultant Paediatric Gastroenterologist and Hepatologist \\ Department of Digestive Disease Centre, \\ Norvic International Hospital, \\ Thapathali, Kathmandu, Nepal \\ Email: binitajoshi9@gmail.com}

DOI: $10.3126 /$ jnps.v40i2.29321

Submitted on: 2020-06-6

Accepted on: 2020-06-23

\section{Acknowledgements: None}

Funding: Nil

Conflict of Interest: None declared

Permission from IRB: Yes

To cite this article: Joshi $\mathrm{BG}$, Ghimire M. Diagnostic yield of upper gastrointestinal endoscopy in children: A three years experience. J Nepal Paediatr Soc. 2019;40(2):87-92.

\section{ABSTRACT}

Introduction: Gastrointestinal disorders are very common in paediatric population. Upper Gastrointestinal Endoscopy procedures have increased dramatically worldwide and have contributed in identification of various gastrointestinal disorders along with therapeutic benefits. However, it is recently being established in paediatric population in Nepal and proper data is scarce. This study was aimed to assess upper gastrointestinal endoscopy with respect to its indications and diagnostic yield at a tertiary centre over a three years period.

Methods: This is a retrospective observational study where data of all paediatric patients between the age group $0-15$ years having various gastrointestinal problems who underwent upper gastrointestinal endoscopy from March 2013 - Feb 2016 in our centre were analysed.

Results: Among 270 patients, males comprised $60 \%$ and females comprised $40 \%$. Age range was $0-15$ years and majority were from the age group between 10 to 15 years $(66.2 \%)$. Most common indications for endoscopy were chronic abdominal pain (58.8\%), acute epigastric pain $(18.5 \%)$, followed by failure to thrive (7\%). Abnormal findings were detected in 250 patients $(92.5 \%)$; gastroduodenitis $(28.14 \%)$, antral gastritis $(18.51 \%)$, erosive gastritis $(15.92 \%)$, duodenitis $(9.25 \%)$, hiatus hernia $(7.4 \%)$, varices $(5.5 \%)$ were common findings. Histopathologically, chronic gastritis and duodenitis (72\%) were common findings followed by acute gastritis and giardiasis. Among 80 patients who underwent RUT, $50 \%$ each had positive and negative results.

Conclusion: Chronic abdominal pain remains common gastrointestinal problem in children. With the advent of upper gastrointestinal endoscopy various gastrointestinal problems can be identified and managed accordingly. Along with the facility of histopathology, diagnostic yield and outcome is further enhanced.

Keywords: Chronic abdominal pain; Gastroduodenitis Paediatrics; Upper Gastrointestinal Endoscopy

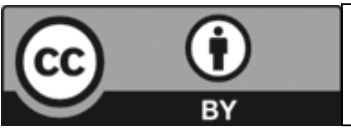

This work is licensed under creative common attribution 3.0 license 


\section{INTRODUCTION}

Once stated by Sir Freeman, a British Paediatric Surgeon, "The need for paediatric endoscopy is well established and the indications will likely increase", has become the reality at present. ${ }^{1}$ Since its dawn from 1970s, paediatric esophagogastroduodenoscopy has evolved from a rare procedure in the operating room to a routine outpatient procedure with broader diagnostic and therapeutic utility of gastrointestinal tract in children. ${ }^{2,3}$ Over the past 30 years, paediatric gastroenterology has emerged as a subspecialty in many countries and increased practice has led to issuing guidelines by the NASPGHAN, ESPGHAN in 1999 for trainees to ensure competence in the field of paediatric gastroenterology and training paediatric endoscopy. ${ }^{3-6}$ A 12 - fold increase in the rate of upper endoscopic procedures from $7.9 \%$ to 95.2\% procedures per 100,000 children per year between 1985 - 2005 has been reported by Franciosi et al. ${ }^{2}$ However, in developing countries, this diagnostic modality is still being under-utilised which can be attributed to factors such as lack of knowledge regarding its utility in paediatric population, insufficient competent manpower and resources such as paediatric friendly scopes and suites, and associated exorbitant costs.

In Nepal, there are very few centres where paediatric gastroenterologists perform esophagogastroduodenoscopies in children. Our institute is one of those few centres where upper gastrointestinal endoscopies are being facilitated by paediatric gastroenterologist in children from 0 - 18 years with paediatric friendly scopes for diagnostic as well as therapeutic purposes. Here we opted to evaluate upper gastrointestinal endoscopy in terms of its indications and diagnostic yield over a three years period at our private hospital such that awareness can be raised amongst the paediatricians and general physicians as to benefit the children also from developing countries from this state of art diagnostic modality.

\section{METHODS}

This is a retrospective observational study conducted at one of the referral centres of the capital of our country, Nepal. All paediatric patients with various gastrointestinal problems between the age group of 0-18 years who underwent upper GI endoscopy for the first time and consented for the study were included. The study was conducted for a period of three years from March 2013 to February 2016. All procedures were performed using Endoscope of Olympus model GIF-Q180 with insertion tube outer diameter of $8.8 \mathrm{~mm}$, Pentax EG-2790I and EG-1690K 2.0 with insertion diameter of $9 \mathrm{~mm}$ and $5.4 \mathrm{~mm}$ respectively by paediatric gastroenterologist. After explaining the purpose and potential hazards of procedure, a written informed consent was taken from the patient's guardians. Mode of anaesthesia was decided according to the patient's age and level of cooperation. For sedation, lidocaine 15\% aerosol spray, intravenous midazolam and ketamine were used as per necessity. Demographic data including age and sex, indications for UGI endoscopy were recorded for each patient. Endoscopic findings along with biopsy samples taken for histopathology and RUT were documented for same patients. The collected data were entered into SPSS version and analysed through statistical program. Frequencies of various indications, endoscopic findings and biopsy results were calculated respectively.

\section{RESULTS}

Among 270 total patients who underwent UGI endoscopy, 164 were male patients $(60 \%)$ and 106 were female $(40 \%)$ patients. From 0 - 15 years age groups, 172 patients were between (10 years - 15 years) age groups (Table 1).

Various gastrointestinal problems were encountered as an indication for UGI endoscopy. Most common indications were chronic abdominal pain $(58.8 \%)$ and epigastric pain (18.5) followed by failure to thrive $(7.0 \%)$, reflux $(5.1 \%)$, recurrent vomiting $(3.3 \%)$, splenomegaly with pancytopenia $(2.2 \%)$. Gastrointestinal bleeding in the form of melena $(0.4 \%)$, haematemesis $(0.7)$, and both $(1.5 \%)$ were

Table 1. Age $(n=270)$

\begin{tabular}{|lr|}
\hline AGE & No. $(\mathbf{\%})$ \\
\hline$<1$ month & $1(0.3)$ \\
1 month $-<12$ months & $2(0.7)$ \\
1 year $-<10$ years & $88(32.5)$ \\
10 years -15 years & $172(63.7)$ \\
$>15$ years & $7(2.5)$ \\
\hline
\end{tabular}


Table 2. Indications for endoscopy $(n=270)$

\begin{tabular}{|lr|}
\hline Indications & No. (\%) \\
\hline Chronic abdominal pain & $159(58.8)$ \\
Acute epigastric pain & $50(18.5)$ \\
Failure to thrive & $19(7.0)$ \\
Reflux & $14(5.1)$ \\
Recurrent vomiting & $9(3.3)$ \\
Splenomegaly with pancytopenia & $6(2.2)$ \\
Gastrointestinal bleeding & \\
a) Hematemesis & $2(0.7)$ \\
b) Melena & $1(0.4)$ \\
c) Hematemesis and melena & $4(1.5)$ \\
Corrosive ingestion & $3(1.1)$ \\
Portal Cavernoma & $2(0.7)$ \\
Chronic liver disease & $1(0.4)$
\end{tabular}

identified. Corrosive ingestion (1.1\%) was also one of the indications. [Table 2]

Abnormal findings were detected in 250 patients $(92.5 \%)$ and normal findings were seen in 20 subjects $(7.40 \%)$. Gastroduodenitis $(28.14 \%)$, antral gastritis (18.51), erosive gastritis (15.92\%) were most commonly identified findings. Similarly, hiatus hernia $(7.40 \%)$, esophagitis $(2.33 \%)$, esophageal varices $(5.5 \%)$, gastric ulcers $(1.85 \%)$, duodenal ulcers $(2.59 \%)$ and esophageal stricture (1.11\%) were other associated findings. [Table 3]

When biopsy records were reviewed, among 192 patients who had biopsy taken for histopathological examination from stomach, duodenum and esophagus; chronic gastritis (31.25\%) and chronic duodenitis $(39.0 \%)$ were the most frequent

Table 4. Histopathological findings $(\mathrm{n}=192)$

\begin{tabular}{|cr|}
\hline Histopathological findings & No $(\%)$ \\
\hline Stomach & $60(31.25)$ \\
a) Chronic gastritis & $20(10.41)$ \\
b) Acute gastritis & \\
Duodenum & $75(39.0)$ \\
a) Chronic duodenitis & $3(1.56)$ \\
b) Acute duodenitis & $16(8.34)$ \\
c) Giardiasis & $14(7.3)$ \\
d) Marsh & $8(4.1)$ \\
1 & $1(0.5)$ \\
2 & $5(2.6)$ \\
3a & $3(1.56)$ \\
Normal esophagus & $1(0.52)$ \\
Reflux esophagitis &
\end{tabular}

Table 3. Endoscopic findings $(n=270)$

\begin{tabular}{|lc|}
\hline Endoscopic findings & No. (\%) \\
\hline Gastroduodenitis & $76(28.14)$ \\
Antral gastritis & $50(18.51)$ \\
Erosive gastritis & $43(15.92)$ \\
Duodenitis & $25(9.25)$ \\
Normal & $20(7.40)$ \\
Hiatus hernia & $20(7.40)$ \\
Esophagitis & $06(2.33)$ \\
Esophageal varices & \\
a) Grade I & $06(2.22)$ \\
b) Grade II & $02(0.74)$ \\
c) Grade III & $03(1.11)$ \\
d) Grade IV & $04(1.48)$ \\
Ulcers: & \\
a) Gastric & $05(1.85)$ \\
b) Duodenal & $07(2.59)$ \\
Esophageal stricture & $03(1.11)$
\end{tabular}

findings. Other findings demonstrated were acute gastritis $(10.41 \%)$, giardiasis $(8.34 \%)$, Marsh grading $(7.3 \%)$, acute duodenitis $(1.56 \%)$, reflux esophagitis $(0.52 \%)$. Normal histopathology was seen in $(1.56 \%)$ of patients. [Table 4] Samples from antrum were also taken for purpose of RUT in order to detect $H$. pylori. From 80 total samples there was $50 \%$ each of positive and negative results.

\section{DISCUSSION}

Gastrointestinal problems are important healthcare concern in paediatric population as it can impede daily functioning of child and can be associated with serious illnesses. UGI endoscopy plays a vital role in identifying and managing such cases which in turn can also be beneficial to alleviate anxiety of patient and their family.

Technical advancement like fibre optic and video technology with paediatric friendly scopes along with anaesthesia has made it possible to examine even the premature infants and severely sick patients from first day of birth. ${ }^{7}$ In our study, children from age group 10 to 15 years had the highest frequency of endoscopy done which is compatible to studies from Pakistan and Bangladesh. ${ }^{8,9}$ Youngest one was 21 days old neonate to undergo UGI endoscopy at our institution. Majority of them were males $(60 \%)$ similar to reports by Lee WS et al. ${ }^{5}$ and Thapa SB et al. ${ }^{10}$ 
The indications for scoping children are more or less similar to those in adults. However, it is very unlikely to localise the upper GI tract symptoms by infants and children and there are number of non specific signs and symptoms which may prompt upper endoscopy in young children including failure to thrive, limitation of usual activities, unexplained irritability and anorexia. Ingestion of foreign body and caustic substances are two other instances which occur more commonly in paediatrics and may require endoscopy. ${ }^{11-13}$ Among the various indications for UGI endoscopy, chronic abdominal pain $(58.8 \%)$ was the most common cause identified in our study. Chronic abdominal pain (CAP) is the term preferred now over recurrent abdominal pain from 2005 and is defined as long lasting or intermittent or constant abdominal pain that is functional or organic for 12 weeks. ${ }^{14,15}$ Data from PEDS-CORI indicate that abdominal pain was the indication in $38 \%$ of 17,180 endoscopies in North America. ${ }^{16,17}$ A study from Nepal by Joshi et al. also had similar finding with $84 \%$ chronic abdominal cases undergoing UGI endoscopy. ${ }^{18}$ Our finding is consistent with studies by Khan et al. and Karim B et al. ${ }^{8,9}$ CAP is reported in $10-12 \%$ of school aged children in developing countries. Rahul and Khan reported CAP in $11.5 \%$ of Bangladesh school children. ${ }^{19}$ Despite the high prevalence of CAP estimated at $13 \%$ of middle school students and $17 \%$ of high school students, there are no evidence based guidelines for its evaluation. The ability to view the GI tract is believed to be the best diagnostic method. ${ }^{17}$

Failure to thrive and short stature are also major indications for endoscopy in children. Celiac disease has been identified as one of the commonest etiologies for growth failure in young children. Endoscopy allows identification of gross mucosal changes that are markers of enteropathy and also facilitates obtaining biopsy samples from duodenum for histology. ${ }^{10,20,21}$ A Study from Pakistan has demonstrated failure to thrive as most common indication at their centre. ${ }^{8} 50 \%$ cases of failure to thrive and short stature were indication in a Sudanese study by Sabir et al. ${ }^{22}$ whereas we had $7 \%$ of total cases who underwent endoscopy for the same.

In our series, gastrointestinal bleeding was observed in $2.6 \%$ patients unlike in another study from Nepal where it was the most common indication identified in $27.6 \%$ cases. ${ }^{10}$ Franciosi et al. have mentioned that the proportion of GI bleeding has declined significantly from $34 \%$ to $5 \%$ in contrast to increased rate of abdominal pain from $23 \%$ to $43 \%$ in his series over 20 years. $^{2}$

The current study illustrates diagnostic yield of $92.5 \%$ among 270 total subjects which is in contrast to data by Thapa SB et al. ${ }^{10}$ and Mudawi et al. ${ }^{23}$ whereas it corroborates with finding of study by Zuleta et al. ${ }^{24}$ Gastroduodenitis $(28.14 \%$ ) was the commonest finding in children in our series followed by antral and erosive gastritis respectively. Findings are similar to the study by Zuleta et al. ${ }^{24}$ performed in Colombia, however most of the studies have shown varices as their common outcomes ranging from $16 \%{ }^{23}$ to $16.6 \%{ }^{18}$ and $44.6 \%{ }^{9}$ respectively. Reefy $\mathrm{M}$ et al. also identified varices in $32(7.15 \%)$ cases as a cause of UGI bleed. ${ }^{25}$

Another purpose of endoscopy is to avail biopsy sample for histopathological studies along with gross examination of the GI tract. ESGE/ ESGPGHAN guidelines suggest routine tissue sampling even in the absence of visible endoscopic abnormalities in all children undergoing EGD. ${ }^{26}$ However, it is of controversy regarding carrying out a duodenal biopsy regardless of indications for endoscopic and macroscopic findings. Many studies have shown that unsuspected duodenal pathology can be found in routine duodenal biopsies. A study on a paediatric population showed that a routine duodenal biopsy yielded pathological findings in $17.4 \%$ and unexpected findings reported such as giardiasis (4.9\%) and H. pylori (6.5\%). ${ }^{27} \mathrm{In}$ current series, 192 subjects had their biopsies taken from stomach (81), duodenum (110) and esophagus (1) for histopathology. Chronic gastritis (31.25\%) and chronic duodenitis $(39.0 \%)$ were superior to other findings such as acute gastritis and duodenitis. Giardiasis was identified in $8.34 \%$ samples in our study which in addition to its acute symptoms has strong association with malnutrition, wasting and stunting. In developing countries, the prevalence of human giardiasis commonly ranges from $20-30 \%$ of the population, with reports of $100 \%$ in some population, and $3-7 \%$ in developed countries. $^{28}$ 
The histological spectrum of the lesions in celiac disease ranges from a slight villous flattening to a decreased V:C ratio, crypt hyperplasia, variable plasma cell and marked increased in the intraepithelial count. ${ }^{27,29}$ Histopathology was helpful in diagnosing $2.6 \%$ cases of celiac disease in our series presenting with failure to thrive. A study by Yaccha SK et al. in 2007 has mentioned increasing trend for diagnosis from 130 (1996-2000) compared to 517 (2001-2005). ${ }^{30}$

H. pylori infection is common all over world with varying rate of incidence and prevalence in childhood by nation and regions in same country. It is postulated that $\mathrm{H}$. pylori infection is mainly acquired during childhood and once established may persist throughout life. Diagnosis of H. pylori should be based on positive histopathology, rapid urease test or culture. It is highly recommended to take biopsies not only for histopathology but also for RUT and culture and that should be taken from both antrum and corpus. ${ }^{7}$ From 80 samples taken from antrum for RUT, we had 50\% positive results which were treated with triple therapy subsequently.

\section{CONCLUSIONS}

Our experience shows a large proportion of children with chronic abdominal pain as primary indication for UGI endoscopy. However, failure to thrive, acute epigastric pain and UGI bleed should also be taken into account in children for performing endoscopies. With very few studies on paediatric UGI endoscopy in our country, our study shows a remarkable data regarding it's diagnostic yield in our children. Biopsies from GI tract can contribute to the diagnostic yield and outcomes of disease hence should be facilitated whenever need be. More importantly, awareness amongst paediatricians in our country regarding the role of this diagnostic and therapeutic modality is the need of the hour for timely referral and welfare of children.

\section{REFERENCES}

1. Gilger MA. Gastroenterologic endoscopy in children: past, present, and future. Curr Opin Pediatr. 2001;13(5): 429-34. DOI: 10.1097/00008480-200110000-00008

2. Franciosi JP, Fiorino K, Ruchelli E, Shults J, Spergel J, Liacouras CA et al. Changing Indications for Upper Endoscopy in Children over a 20 Year Period. J Pediatr Gastroenterol Nutr. 2010;51(4):443. DOI: 10.1097/MPG. 0b013e3181d67bee

3. Friedt M, Welsch S. An update on paediatric endoscopy. Eur J Med Res. 2013;18(1):24. DOI: 10.1186/2047-783X-18-24

4. Kim YJ. General considerations and updates in paediatric gastrointestinal diagnostic endoscopy. Korean J Pediatr. 2010 Sep 1;53(9):817-23. DOI: 10.3345/kjp.2010.53.9.817

5. Lee WS, Zainuddin H, Boey CC, Chai PF. Appropriateness, endoscopic findings and contributive yield of pediatric gastrointestinal endoscopy. World J Gastroenterol. 2013;19(47):9077. DOI: 10.3748/wjg.v19.i47.9077

6. El-Mouzan MI, Al-Mofleh IA, Abdullah AM, Al-Rashed RS. Indications and yield of upper gastrointestinal endoscopy in children. Saudi Med J. 2004;25(9):1223-5. DOI: 10.1155/2015/820340

7. Kostovski A, Zdraveska N. Indications for gastrointestinal endoscopy in children. Slov Med J. 2013:18;82.

8. Khan MR, Ahmed S, Ali SR, Maheshwari PK, Jamal MS. Spectrum of upper GI endoscopy in paediatric population at a tertiary care centre in Pakistan. Open J Pediatr. 2014;4(03):180.

9. Karim B. Upper gastrointestinal endoscopy in children-an experience at a paediatric gastroenterology unit. Mymensingh Med J. 2003;12(2):124-7. DOI: 10.5409/wjcp.v4.i4.113

10. Thapa SB, Sharma AK. Findings of Paediatric Upper Gastrointestinal Endoscopy at a Tertiary Care Centre. J Nepal Paediatr. 2016;35(2):123-8. DOI: 10.3126/jnps.v35i2.13595

11. Lee KK, Anderson MA, Baron TH, Banerjee S, Cash BD, Dominitz JA, et al. Modifications in endoscopic practice for paediatric patients. Gastrointest Endosc. 2008;67(1):1-9. doi:10.1016/j.gie.2007.07.008

12. Lightdale JR, Acosta R, Shergill AK, Chandrasekhara V, Chathadi K, Early D, et al. Modifications in endoscopic practice for paediatric patients. Gastrointest Endosc. 2014;79(5):699-710. doi:10.1016/j.gie.2013.08.014 
13. AlabdAlrazzak B, Husien T, Preston DL, Elitsur Y. Upper endoscopy in children: do symptoms predict positive findings? Clinpediatr (Phila). 2014;53(5):474-8. doi:10.1177/0009922814528034.

14. Sathiyasekaran M. Management of Recurrent Abdominal Pain: Have we Reached the end of the Tunnel. Indian Pediatr. 2015;52(10):841-2. DOI: 10.1007/s13312-015-0729-4

15. Di Lorenzo C, Colletti RB, Lehmann HP, Boyle JT, Gerson WT, Hyams JS, et al. Chronic Abdominal Pain in Children: A Clinical Report of the American Academy of Paediatrics and the North American Society for Paediatric Gastroenterology, Hepatology and Nutrition: American Academy of Paediatrics Subcommittee on Chronic Abdominal Pain and NASPGHAN Committee on Abdominal Pain. J Pediatr Gastroenterol Nutr. 2005;40(3):245-8. DOI: $10.1097 / 01 . m p g .0000155367 .44628 .21$

16. Thakkar K, Dorsey F, Gilger MA. Impact of endoscopy on management of chronic abdominal pain in children. Dig Dis Sci. 2011;56(2):488-93. DOI: 10.1007/s10620-010-1315-1

17. Thakkar K, Gilger MA, Shulman RJ, El Serag HB. EGD in children with abdominal pain: a systematic review. Am J Gastroenterol. 2007;102(3):654-61. doi:10.1111/j.1572-0241.01051.x

18. Joshi MR, Sharma SK, Baral MR. Upper GI endoscopy in children-in an adult suite. Kathmandu Univ Med J. 2005; 3(2):111-4. PMID: 16415605

19. Devanarayana NM, Rajindrajith S, deSilva HJ. Recurrent abdominal pain in children. Indian Pediatr. 2009;46(5): 389-99. PMID: 19478352

20. Devlin SM, Andrews CN, Beck PL. Celiac disease. CME update for family physicians. Can Fam Physician. 2004;50(5):719-25. PMCID: PMC2214607

21. Holtmeier W, Caspary WF. Celiac Disease. Orphanet J Rare Dis. 2006 Mar 1;1:3. doi:10.1186/1750-1172-1-3

22. Sabir OM, Gadour MO. Upper gastrointestinal endoscopy in Sudanese infants and children. Sudan JMS. 2007;2(2): 91-5. PMID: 20187556

23. Mudawi HM, El Tahir MA, Suleiman SH, Eltaybe NH, Gamer NM, Abdallha FA, et al. Paediatric gastrointestinal endoscopy: experience in a Sudanese university hospital. East Mediterr Health J. 2009;15(4):1027-31. PMID: 20187556

24. Zuleta G, Alonso M, Ruiz Morales ÓF, Riveros J. Diagnostic usefulness of upper gastrointestinal endoscopy for patients under 18 years of age. Rev Col Gastroenterol. 2014;29(2):112-6.

25. Rafeey M, Shoaran M, Majidy H. Diagnostic endoscopy and clinical characteristics of gastrointestinal bleeding in children: a 10-year retrospective study. Iran Red Crescent Med J. 2013;15(9):794. doi:10.5812/ircmj.7075

26. Tringali A, Thomson M, Dumonceau JM, Tavares M, Tabbers MM, Furlano R, et al. Paediatric gastrointestinal endoscopy: European society of gastrointestinal endoscopy (ESGE) and European society for paediatric gastroenterology hepatology and nutrition (ESPGHAN) guideline executive summary. Endoscopy. 2017;49(01): 83-91. doi: $10.1055 / \mathrm{s}-0042-111002$

27. Serra S, Jani PA. An approach to duodenal biopsies. J ClinPathol. 2006;59(11):1133-50. doi: 10.1135/jcp. 2005.031260

28. Halliez MC, Buret AG. Extra-intestinal and long term consequences of Giardia duodenalis infections. World J Gastroenterol. 2013;19(47):8974. doi:10.3748/wjg.v19.i47.8974

29. Kelly CP, Bai JC, Liu E, Leffler DA. Advances in diagnosis and management of celiac disease. Gastroenterology. 2015;148(6):1175-86. doi: 10.1053/j.gastro.2015.01.044

30. Yachha SK. Celiac disease: India on the global map. J Gastroenterol Hepatol. 2006;21(10):1511-3. doi:10.1111/j. 1440-1746.2006.04560.x 